
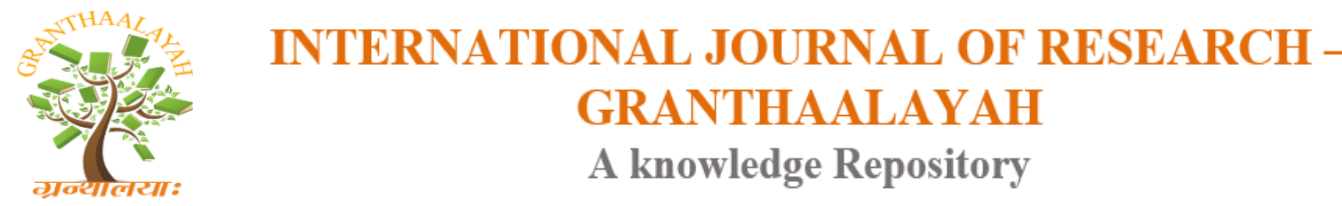

Management

\title{
EFFECTIVE CRM ENHANCEMENT STRATEGIES FOR INDIAN RETAIL MARKET
}

\author{
Henry Ker-Chang Chang ${ }^{1}$, Hardy Lin ${ }^{2}$, Nilesh Patankar ${ }^{* 3}$ \\ ${ }^{1}$ Professor, Dept. Information Management, Chang Gung University, Taiwan \\ ${ }^{2}$ Professor, Dept. Information Management, Chihlee University of Technology, Taiwan \\ ${ }^{* 3}$ Graduate Student, School of Business, Chang Gung University, Taiwan
}

DOI: https://doi.org/10.29121/granthaalayah.v5.i4.2017.1790

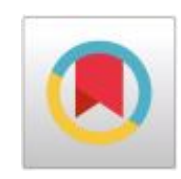

\begin{abstract}
The retail sector in India is one of the fast paced moving sectors and as per the experts; retail sector market size growth is expected to USD 1.3 trillion by 2020. Among India's most attractive features for doing business, investors rated its vast domestic market and availability of cheap labor as most appealing which made India as a most promising emerging market among Asian countries and has become Centre of attraction for investors all around the globe. Taiwan is also not behind the race. After President Tsai's proposal of "new southbound policy", many investors from Taiwan including Terry Gou have shown a keen interest in Indian market. Though the potential growth is immense, due to ever increasing competition retailers are always under pressure to engage their customers more efficiently than before. The purpose of this paper is to explain incorporation of RFM analysis techniques to provide key insights to the retailers. It is expected that with the proposed approach retailers and investors from India and Taiwan will be able to create customer focused sales driven strategies to create amazing shopping experience for its customers.
\end{abstract}

Keywords: Emerging Market; RFM Analysis; FDI Policy; New Southbound Policy; Retail Sector.

Cite This Article: Henry Ker-Chang Chang, Hardy Lin, and Nilesh Patankar. (2017). "EFFECTIVE CRM ENHANCEMENT STRATEGIES FOR INDIAN RETAIL MARKET." International Journal of Research - Granthaalayah, 5(4), 12-23. https://doi.org/10.29121/granthaalayah.v5.i4.2017.1790.

\section{Introduction}

The Indian Retail Market is one of the fastest growing in the world. Retail Market in India is expected to grow to USD 1.3 trillion by 2020, registering a Compound Annual Growth Rate (CAGR) of 16.7 per cent over 2015-20 [1]. 
India is the fifth largest preferred retail destination globally. The country is among the highest in the world in terms of per capita retail store availability. India's retail sector is experiencing exponential growth, with retail development taking place not just in major cities and metros, but also in Tier-II and Tier-III cities. Healthy economic growth, changing demographic profile, increasing disposable incomes, urbanization, changing consumer tastes and preferences are the other factors driving growth in the retail market in India.

The government of India has introduced reforms to attract Foreign Direct Investment (FDI) in retail industry. The government has approved 51 per cent FDI in multi-brand retail and increased FDI limit to 100 per cent (from 51 per cent) in single brand retail.

It also finds major gains in key areas such as macroeconomic stability, political and social stability, and the government's efforts to ease doing business. The improvements in India's macroeconomic indicators, accompanied with the ongoing efforts to revitalize growth have offered new hope to investors.

Taiwanese investors have also joined the bandwagon to do major investments in India. TaiwanIndia relationship has made significant progress for the past decades. Taiwan president Tsai Ingwen's "new southbound policy" in the hope of reducing Taiwan's economic dependence on China and creates opportunities for Taiwanese businesses in Southeast Asia and India has also played a vital role. Economic cooperation in areas of trade, investment and industry between India and Taiwan has been very close in recent years. Bilateral trade has grown nearly five-fold from USD 1.19 billion in 2001 to USD 5 billion in 2015. During the same period, India's export of commodities to Taiwan increased from USD 550 million to USD 3 billion, while India's imports of commodities from Taiwan increased from USD 640 million to USD 2 billion. India ranks as Taiwan's 16th largest export destination and 21st largest source of import. The bilateral trade relationship is further enhanced by frequent exchanges of visits by business delegations.

As of the end of 2015, around 90 Taiwanese companies have set up business operations in India, with the total investment amount of USD 311 million in the fields of information and communication technology, medical devices, automobile components, machinery, steel, electronics, construction, engineering, financial services, etc. The Taiwan Electrical and Electronic Manufacturers' Association has selected two sites in Bengaluru and Greater Noida to build electronics manufacturing clusters with a view to deepening supply chain collaboration with Indian partners.

The challenge for retailers is that the Customer relationship management in retailing has transformed and paved the way for customer experience management (CEM). The uniqueness of Indian customers and their changing preferences have forced retailers to make continuous efforts in understanding customer's perceptions and create diversified and innovative retail formats. The Thumb rule in today's modern business is very simple of "either differentiate or die."

Google CEO Eric Schmidt stated in Techonomy conference in 2010 [2] that "every two days, we create as much information as we did from the dawn of civilization up until 2003. The real issue is user-generated content". This is absolutely true. The Retail Market has made a paradigm shift in strategy from being product centric to consumer centric in the past decade. Also, there is a 
rapid adoption of Internet technologies. New sales channels and additional customer touch points are leading to a profusion of data. Websites, mobile devices and social networks are the new media of interaction between retailers and customers, and also among various customers wherein earlier the traditional data collected from Points of Sale (PoS) was the only source of information. The volume, variety and velocity of data being produced in all areas of the retail market is growing exponentially, creating opportunity for retailers to withstand the global competition and formulate the compelling customer centric differentiation strategies, if they analyze this data effectively.

This paper proposes RFM (Recency, Frequency, Monetary) analysis and data mining technique [11] with the integration of clustering to help retailers create effective CRM enhancement strategies. It is expected that with the proposed approach retailers and investors from India and Taiwan will be able to create customer focused merchandising, promotional and sales driven strategies to create amazing shopping experience for its customers and forge tighter connections between customers.

This paper will address the following research questions:

Q1. Can we identify drivers of profitability in retail business?

Q2. Can customer database be segmented to identify which customers are the most profitable?

\section{Literature Review}

\subsection{RFM Analysis}

RFM analysis is a marketing technique used to determine quantitatively which customers are the best ones by examining how recently a customer has purchased (recency), how often they purchase (frequency), and how much the customer spends (monetary). RFM analysis is based on the marketing axiom that "80 per cent of your business comes from 20 per cent of your customers [3]."

Khajvand et al. [4] showed that customer lifetime value can be estimated based on RFM analysis of customer purchase behavior. Today's retail market is in the midst of great changes. The current competitive set is under fierce competition from new and emerging venues. Yesterday's winners may be losers today as the customer preference is changing over the years. The continuous increasing competition is forcing retailers to deal with their consumers very efficiently.

\subsection{Some Researches about Role of Data Mining in Retail Sector}

Ramageri et al. [5] indicated that the data mining is proved to be one of the important tools for identifying useful information from very large amount of data bases in almost all the industries.. Industries are using data mining to increase revenues and reduce costs. Further in her research paper she mentioned about data mining applications in retail industry for customer segmentation and target marketing. 
Patil [6] in his research paper mentioned about Data mining techniques for Customer Relationship Management in organized Retail industry to Integrating retailer, suppliers and customers for better customer service.

In an exclusive study report released on 2 September, 2013 at New Delhi edited by Parthapratim et al. [7] which talked about Enhancing Trade, Investment and Co-operation between India and Taiwan. As per the study report, India and Taiwan exhibit strong complementarities in investment. Taiwan is a major investor in Asian countries and it has significant horizontal and vertical FDI in several countries in the region. India, on the other hand, is looking to attract more FDI to cover its current account deficit and to boost its manufacturing sector. Taiwanese companies have successfully set up global production networks and India wants to be part of the global production network and high-value manufacturing. These synergies and complementarities have ensured that trade and investment flows between the two countries can be mutually beneficial.

As per the report published in The Economic Times (India) on May 2016, Taiwan's Tech Major Acer has sought approval from the Indian government to convert its local business model to retail from wholesale, as the Taiwanese electronics firm seeks to set up outlets to sell PCs and handsets directly to consumers here [8].

As per the another report published in The Economic Times (India) on Aug. 2015, Foxconn, the world's biggest contract manufacturer, said that it is making a long-term investment commitment to India, with plans to bring in the entire supply-chain ecosystem as it looks to go beyond product assembly [9]. Foxconn, which makes iPhone, iPad and other Apple products, is in talks with Adani Group and other Indian firms to set up manufacturing factories in India. Foxconn Chairman and CEO Terry Gou, on his second visit to India in 45 days, said his company was "very keen to invest" in the country and is in talks to strike partnership with local companies.

In another news report published in Hindu business line on Oct 2015, Taiwanese phone maker ASUS will plan investment into gaming stores and smartphones in India and will also manufacture smart phones in India [10].

Retail is one of the most important business domains for data science and data mining applications because of its prolific data and numerous optimization problems such as optimal prices, discounts, recommendations and stock levels that can be solved using data analysis methods. The rise of Omni-channel retail that integrates marketing, customer relationship management, and inventory management across all online and offline channels has produced a plethora of correlated data which increases both the importance and capabilities of data-driven decisions [12].

\section{Research Methodology}

The proposed approach uses RFM analysis in to data mining techniques to provide key insights to the retailers. The purpose is to answer the following questions:

1) Can we identify drivers of profitability in retail business? 
2) Can customer database be segmented to identify which customers are the most profitable?

To answer those questions, the research model of study is as in the Figure 1:
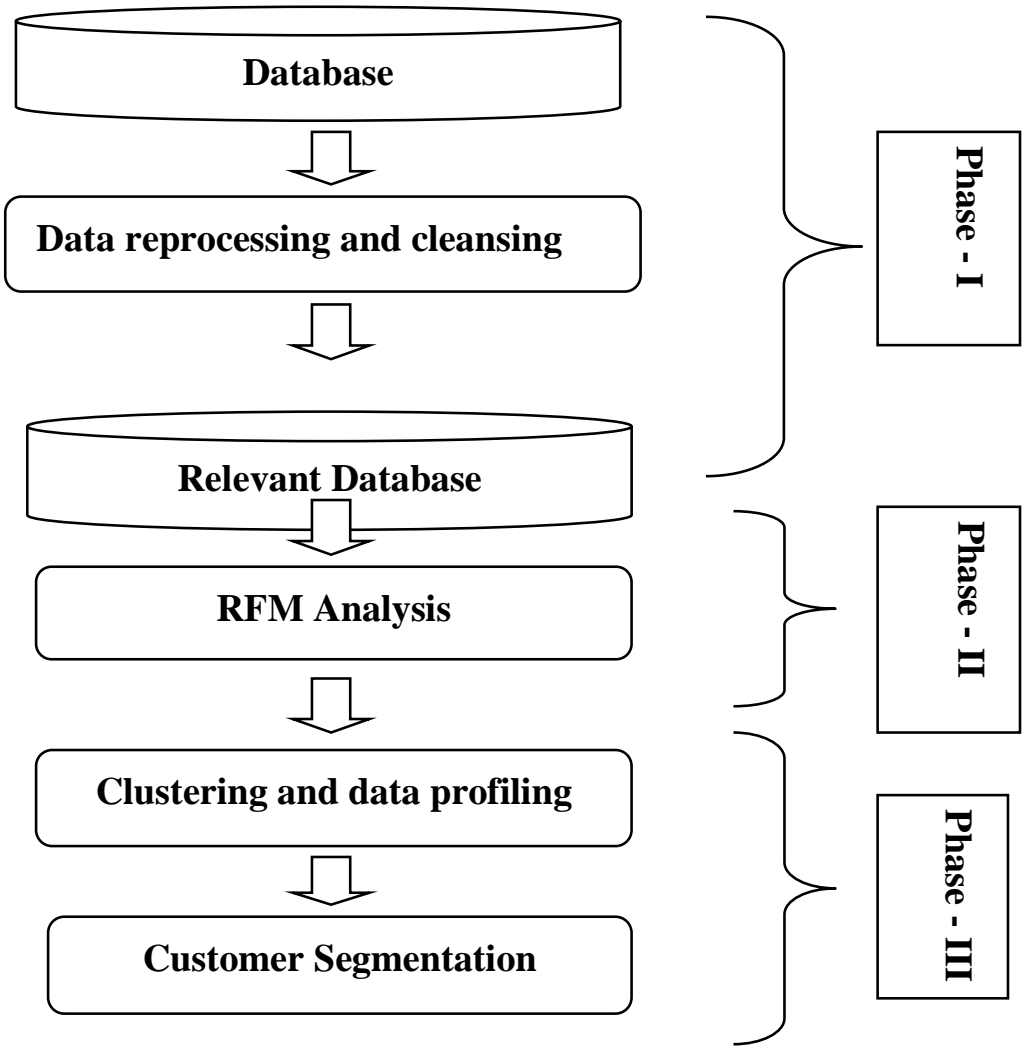

Figure 1: Flowchart of this methodology.

The research model is a three phased model. In the first phase Online retail data is collected and data cleansing is done in order to remove incomplete and irrelevant data and formatted according to the required format for further processing. Second phase involves RFM analysis based on the recency, frequency and monetary attributes of the customers. In the third phase, according to RFM attributes for each customer, data is partitioned in to clusters using K-means clustering and profiling clusters to identify best cluster.

\subsection{RFM model}

RFM model is a 3-dimensional way of classifying or scoring customers to determine top 20 per cent or the best customers. It is based on the $80 / 20$ principle that 80 per cent of revenue comes from 20 per cent of customers. 
There are 3 components of RFM framework: Recency, Frequency, and Monetary.

Recency (R): When was the last time a customer made a purchase order with your business? According to the RFM model, a customer who has recently purchased from you is more inclined to do another purchase that you offer.

Frequency $(\mathrm{F})$ : How regularly does this customer make a purchase with your business? The frequency of a purchase can predict the likelihood and schedule of future purchases.

Monetary Value (M): How much money does this customer spend over a period of time? Customers are then given a score that represents their three ratings across the inputs. The concept is that higher the RFM score, the more likely this customer will purchase from you again.

\subsection{Clustering}

Clustering is the task of grouping a set of objects in such a way that objects in the same group (called a cluster) are more similar (in some sense or another) to each other than to those in other groups (clusters). It is a main task of exploratory data mining, and a common technique for statistical data analysis, used in many fields, including machine learning, pattern recognition, image analysis, information retrieval, bioinformatics, data compression, and computer graphics.

\section{Case Study}

This section presents a case study which demonstrates how our proposed model was applied in the real world data, collected from Indian online E-commerce Company. Using this data, 1000 customers have been clustered using IBM SPSS Statistics tool V.24.0 [13].

\subsection{Data Reprocessing and Cleansing}

Dataset used in this case study was provided by online retail store in India and collected through its channel partner within 2 years period from January 2012 till March 2014. The complete database included purchase details of 1000 customers. The database included many data attributes such as customer ID, first transaction date, last transaction date, quantity, ordering amount. Also customer's personal details such as sex, age, e-mail ids, and telephone numbers were included in the database.

From this E-commerce dataset, unnecessary attributes like e-mail ids, telephone numbers were discarded as it was irrelevant to be used in data mining. The gender attribute was represented as $\mathrm{M}$ and $\mathrm{F}$ instead of male and female. The recency attribute was constructed based on the last order date. The frequency attribute was constructed based on the number of transactions each customer has made within the specified period. Monetary attribute was constructed based on the total amount of money spent by each customer. The relevant database is as shown in Figure 2: 


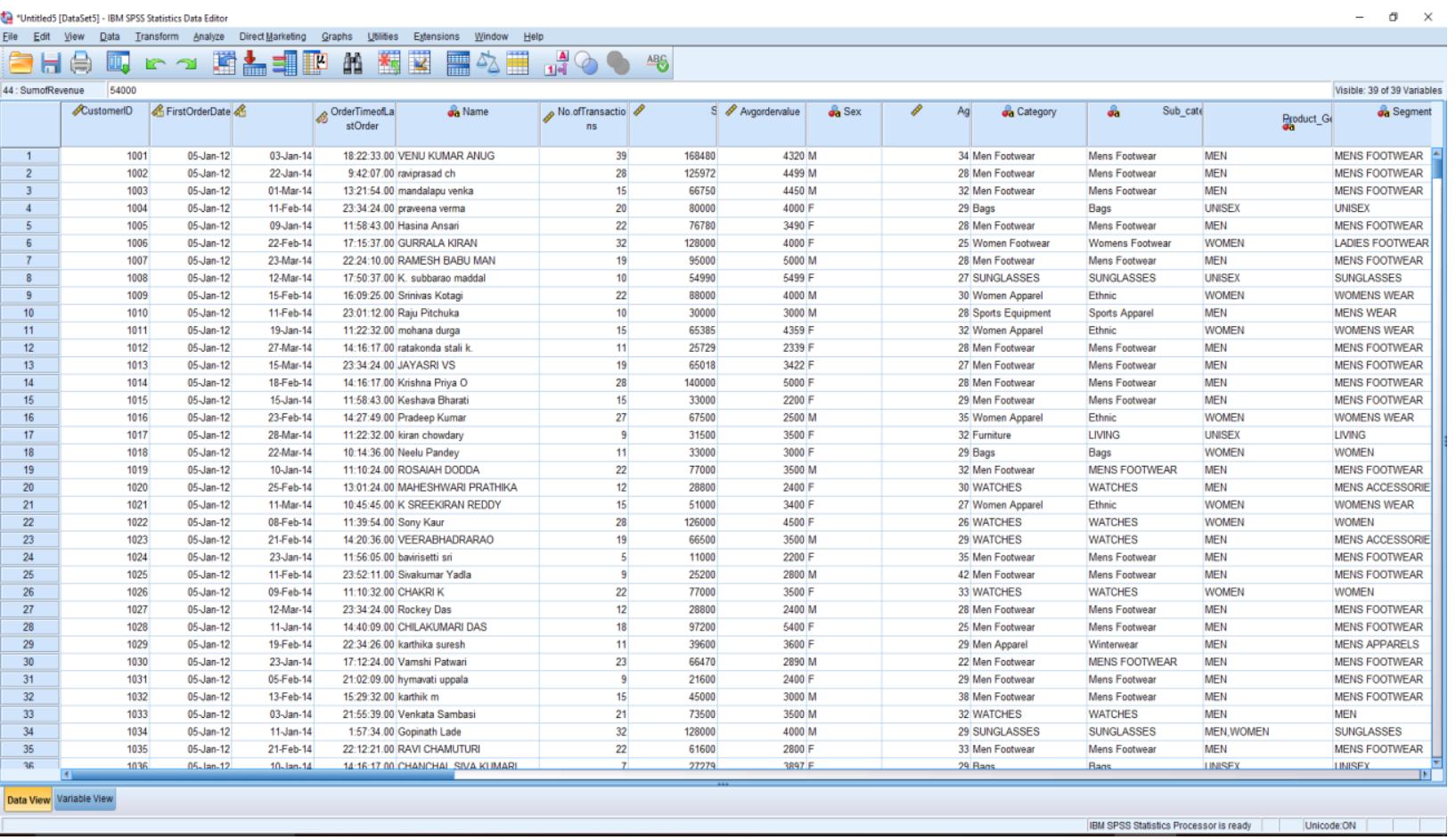

Figure 2: Data base information.

\subsection{RFM Analysis}

All customers were ranked by considering their recency, frequency and monetary values, and they were represented by RFM codes._The following Figure 3 is described as:

\section{Case Processing Summary}

\begin{tabular}{l|l|l|l|l|l|l} 
& \multicolumn{2}{c}{ Valid } & \multicolumn{2}{c}{ Cases } & \multicolumn{2}{c}{ Missing } \\
& $N$ & Percent & N & Percent & N & Percent \\
\hline $\begin{array}{l}\text { Frequency score * } \\
\begin{array}{l}\text { Monetary score * Recency } \\
\text { score }\end{array}\end{array}$ & 1000 & $99.0 \%$ & 10 & $1.0 \%$ & 1010 & $100.0 \%$ \\
\hline
\end{tabular}

Figure 3: RFM is the content. 
The following Figure 4 is as:

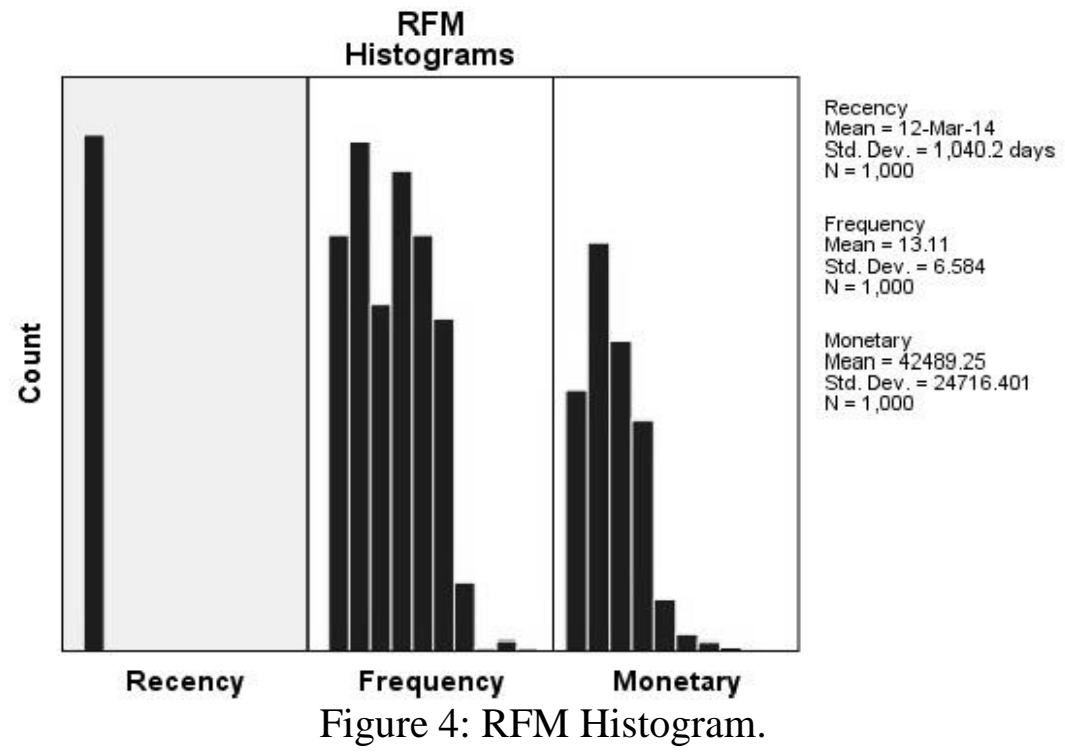

The histograms show the relative distribution of values for the three fields used to calculate recency, frequency, and monetary scores as in Figure 5:
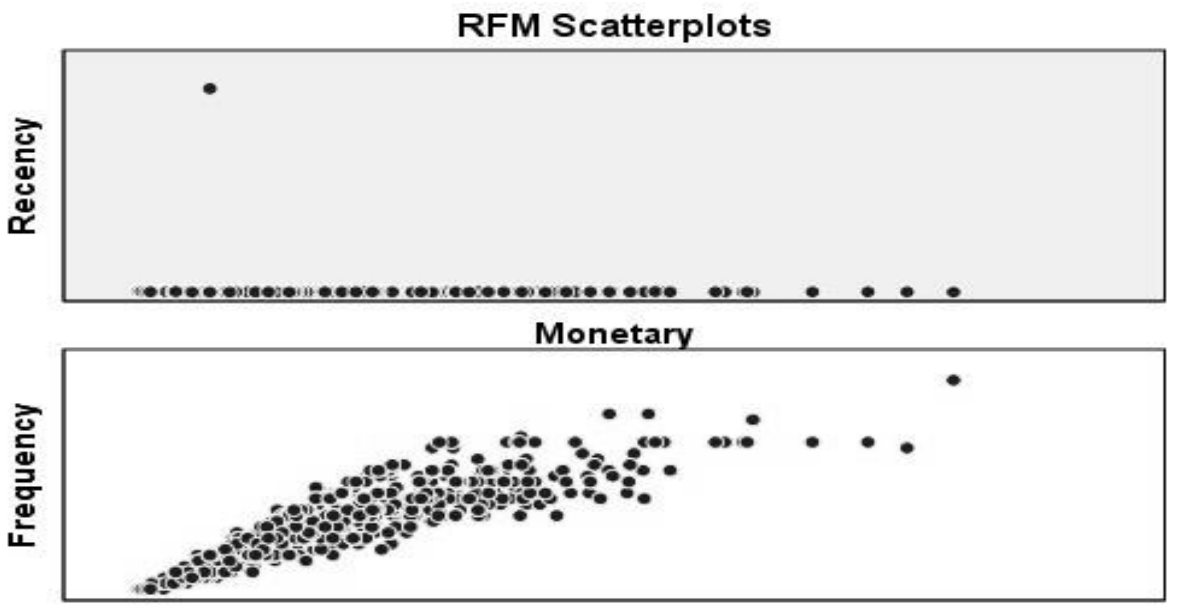

Monetary

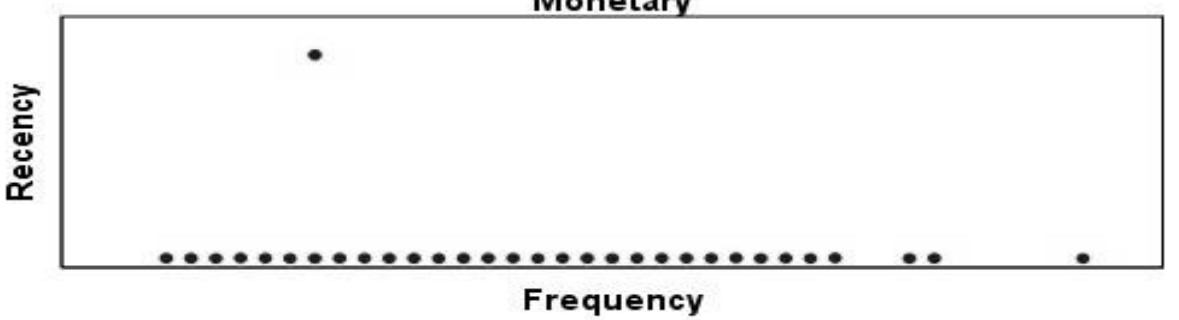

Figure 5: RFM Scatterplots.

These RFM scatterplots in Figure 5 show the relationships between the three variables used to calculate recency, frequency, and monetary scores. 
The score cross tabulation will be listed in Figure 6:

\begin{tabular}{|c|c|c|c|c|c|c|c|c|}
\hline \multicolumn{9}{|c|}{ Frequency score * } \\
\hline \multicolumn{9}{|c|}{ Count } \\
\hline & & & \multicolumn{5}{|c|}{ Monetary score } & \multirow[b]{2}{*}{ Total } \\
\hline \multicolumn{3}{|c|}{ Recency score } & 1 & 2 & 3 & 4 & 5 & \\
\hline \multirow[t]{6}{*}{1} & \multirow[t]{5}{*}{ Frequency score } & 1 & 8 & 8 & 8 & 9 & 7 & 40 \\
\hline & & 2 & 8 & 7 & 9 & 9 & 7 & 40 \\
\hline & & 3 & 9 & 8 & 10 & 8 & 10 & 45 \\
\hline & & 4 & 6 & 7 & 7 & 7 & 6 & 33 \\
\hline & & 5 & 8 & 9 & 9 & 9 & 8 & 43 \\
\hline & \multicolumn{2}{|l|}{ Total } & 39 & 39 & 43 & 42 & 38 & 201 \\
\hline \multirow[t]{6}{*}{2} & \multirow[t]{5}{*}{ Frequency score } & 1 & 7 & 8 & 8 & 8 & 7 & 38 \\
\hline & & 2 & 8 & 8 & 8 & 8 & 8 & 40 \\
\hline & & 3 & 6 & 7 & 7 & 7 & 7 & 34 \\
\hline & & 4 & 7 & 8 & 8 & 7 & 7 & 37 \\
\hline & & 5 & 7 & 9 & 7 & 8 & 8 & 39 \\
\hline & \multicolumn{2}{|l|}{ Total } & 35 & 40 & 38 & 38 & 37 & 188 \\
\hline \multirow[t]{6}{*}{3} & \multirow[t]{5}{*}{ Frequency score } & 1 & 10 & 10 & 11 & 10 & 10 & 51 \\
\hline & & 2 & 13 & 12 & 12 & 12 & 13 & 62 \\
\hline & & 3 & 9 & 10 & 10 & 9 & 11 & 49 \\
\hline & & 4 & 10 & 11 & 11 & 10 & 10 & 52 \\
\hline & & 5 & 9 & 8 & 9 & 9 & 8 & 43 \\
\hline & \multicolumn{2}{|l|}{ Total } & 51 & 51 & 53 & 50 & 52 & 257 \\
\hline \multirow[t]{6}{*}{4} & \multirow[t]{5}{*}{ Frequency score } & 1 & 7 & 7 & 7 & 7 & 7 & 35 \\
\hline & & 2 & 4 & 5 & 5 & 5 & 5 & 24 \\
\hline & & 3 & 7 & 7 & 7 & 9 & 6 & 36 \\
\hline & & 4 & 4 & 5 & 4 & 4 & 5 & 22 \\
\hline & & 5 & 7 & 6 & 8 & 7 & 7 & 35 \\
\hline & \multicolumn{2}{|l|}{ Total } & 29 & 30 & 31 & 32 & 30 & 152 \\
\hline \multirow[t]{6}{*}{5} & \multirow[t]{5}{*}{ Frequency score } & 1 & 9 & 9 & 10 & 11 & 7 & 46 \\
\hline & & 2 & 6 & 7 & 7 & 7 & 7 & 34 \\
\hline & & 3 & 7 & 9 & 7 & 8 & 8 & 39 \\
\hline & & 4 & 9 & 10 & 10 & 9 & 10 & 48 \\
\hline & & 5 & 7 & 7 & 7 & 7 & 7 & 35 \\
\hline & \multicolumn{2}{|l|}{ Total } & 38 & 42 & 41 & 42 & 39 & 202 \\
\hline \multirow[t]{6}{*}{ Total } & \multirow[t]{5}{*}{ Frequency score } & 1 & 41 & 42 & 44 & 45 & 38 & 210 \\
\hline & & 2 & 39 & 39 & 41 & 41 & 40 & 200 \\
\hline & & 3 & 38 & 41 & 41 & 41 & 42 & 203 \\
\hline & & 4 & 36 & 41 & 40 & 37 & 38 & 192 \\
\hline & & 5 & 38 & 39 & 40 & 40 & 38 & 195 \\
\hline & Total & & 192 & 202 & 206 & 204 & 196 & 1000 \\
\hline
\end{tabular}

Figure 6: Frequency score $*$ Monetary score $*$ Recency score Cross tabulation. 


\subsection{Customer Segmentation}

K-means clustering method was employed to group customers with similar RFM values. The $\mathrm{K}$ parameter was set to 8 as in Figure 7 and customers were segmented in eight types as in Figure 8:

Initial Cluster Centers

\begin{tabular}{l|r|r|r|r|r|r|r|r} 
& \multicolumn{7}{c}{} & \multicolumn{7}{c}{ Cluster } & & \\
& 1 & 2 & 3 & 4 & 5 & 6 & 7 & 8 \\
\hline Recency score & 1 & 2 & 5 & 3 & 1 & 4 & 5 & 2 \\
\hline Frequency score & 5 & 5 & 1 & 4 & 1 & 2 & 5 & 1 \\
\hline Monetary score & 5 & 5 & 1 & 1 & 1 & 5 & 5 & 1 \\
\hline RFM score & 155 & 25 & 511 & 341 & 111 & 425 & 555 & 211 \\
\hline
\end{tabular}

Figure 7: K parameter.

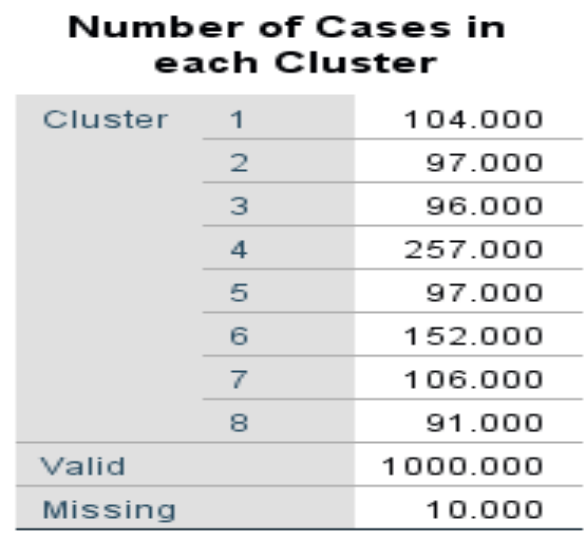

Figure 8: No. of customers in each cluster.

Table 1: Customer Profiling

\begin{tabular}{|l|l|l|l|}
\hline Cluster & Size & RFM pattern & Customer Type \\
\hline C1 & 104 & 155 & First timer \\
\hline C2 & 97 & 255 & Shoppers \\
\hline C3 & 103 & 511 & Churn \\
\hline C4 & 257 & 341 & Spenders \\
\hline C5 & 97 & 111 & Most valuable \\
\hline C6 & 152 & 425 & Frequent \\
\hline C7 & 99 & 555 & Uncertain \\
\hline C8 & 91 & 211 & Valuable \\
\hline
\end{tabular}

There are eight types of customers in Table 1. These eight customer types include most valuable customers, valuable customers, shoppers, frequent customers, first-timers, churn customers, spenders, and uncertain customers. Cluster $\mathrm{C} 1$ falls in first-timer customers who have recently visited for shopping with higher recency but lower buying frequency and lower monetary spending. Customers in $\mathrm{C} 2$ cluster are shoppers as recency is little higher whereas buying frequency and monetary spending is lower. Customers in cluster $\mathrm{C} 3$ have made a high number of 
purchases with high monetary values but not for a long time. Cluster $\mathrm{C} 4$ has customers with higher spending but lower recency and frequency. Cluster C5 contains the most valuable customers, as it consists of customers who have recently made regular purchase with higher buying frequency and higher spending. Cluster C6 has customers who frequently visited but not recently and spending is also lower. Cluster C7 have customers who are uncertain type of customers as they have low buying frequency, lower recency and lower monetary spending. Finally Cluster C8 has valuable customers who have made a high number of purchases with high monetary values recently. As not all customers are the same. So instead of taking a one-size-fitsall approach for marketing, based on the insights explained above retailers can design different marketing strategies for different customer types. With the reference of the segmentation explained in Table 1 retailers can not only maximize opportunities for cross-selling or up-selling, retaining the most valuable and valuable customers but also can identify new business prospects by effectively communicating with the right target group. This in return will maximize ROI on marketing expenditures and ultimately lead to profitability.

\section{Limitations and Further Research}

General database is lower value, some forecast is rare attractive. Right now, big data is very popular, even the usage of big data to forecast is applied recently, so application of big data to find the future E-commerce can be found directly. We believe that the application for big data should be a future idea.

It might also be interesting to note that how other factors influence the predictions. The possible future work can be segmenting customer demographic data (age, gender etc.) using classification rules to predict the customer behavior pattern and even association algorithm can be used for the product recommendations.

\section{Conclusion}

As retail industry has entered the big data era, there are new challenges encountered but at the same time new opportunities are also cropping up. As more retailers compete for customers, there is rigorous need to step up strategies and methods to remain competitive. The aim of this paper is to develop a preliminary conceptual framework to analyze whether RFM model can be applied in retail business and to answer the research questions set at the beginning of the study.

Q1. Can we identify drivers of profitability in retail business?

Overall answer is yes. Though major drivers of profitability is monetary value but recency and frequency also plays vital role in helping retailers to come up with effective marketing strategies by segmenting customers.

Q2. Can customer database be segmented to identify which customers are the most profitable?

With the support of case study in this paper we can suggest that RFM is an effective way to classify customers and segment the database, to analyze most profitable customers. 


\section{References}

[1] India Brand Equity Foundation (IBEF), Indian Retail Industry Analysis, 2015. http://www.ibef.org/industry/indian-retail-industry-analysis-presentation.

[2] Eric Schmidt, Every 2 Days We Create As Much Information As We Did Up To 2003, 2010. https://techcrunch.com/2010/08/04/schmidt-data/.

[3] Margaret Rouse, The definition of RFM analysis, 2005. http://searchdatamanagement.techtarget.com/definition/RFM-analysis.

[4] Mahboubeh Khajvand, Kiyana Zolfaghar, Sarah Ashoori, Somayeh Alizadeh, Estimating Customer Lifetime Value based on RFM Analysis of Customer Purchase Behavior: Case Study, Procedia Computer Science, 3, 57-63, 2011. http://www.sciencedirect.com/science/article/pii/S1877050910003868.

[5] Bharati M. Ramageri, B. L. Desai, Role of Data Mining in Retail Sector, Int. J. Computer Science and Engineering, 5(1), 47-50, 2013. http://www.enggjournals.com/ijcse/doc/IJCSE13-05-01051.pdf.

[6] Subhash B. Patil, Data Mining Techniques for Customer Relationship Management in Organized Retail Industry, 2011.

https://www.academia.edu/2447358/Data_Mining_Techniques_used_in_Retail_Industry?auto=do wnload.

[7] Parthapratim Pal, Kristy Arpita Mukherjee, Tsun-Tzu Hsu, Enhancing Trade, Investment and Cooperation between India and Taiwan, 2013.

http://icrier.org/pdf/enhancing_trade_Investment_cooperation.pdf.

[8] Ruchika Chitravanshi, Acer seeks to reap Make in India perks with switch to retail model and sell, 2016.http://economictimes.indiatimes.com/tech/hardware/acer-seeks-to-reap-make-in-indiaperks-with-switch-to-retail-model-and-sell/articleshow/52409004.cms.

[9] Press Trust of India (PTI), Foxconn Chief Terry Gou: Looking at Long-Term Investments in India,2015.http://economictimes.indiatimes.com/tech/hardware/foxconn-chief-terry-gou-lookingat-long-term-investments-in-india/articleshow/48350037.cms.

[10] Abhishek Law, Asus Betting Big On India Market, July 12016. http://www.thehindubusinessline.com/info-tech/asus-betting-big-on-india market/article8797939.ece.

[11] Gordon S. Linoff, "Data Mining Techniques", (3rd ed.), Willey, New Jersey, March 2011.

[12] Alan Weber, "Data-Driven Business Models", (1st ed.), Thomson, 2005.

[13] David Gillman, "Use SPSS Statistics Direct Marketing Analysis to Gain Insight”, May 2014. http://www.ibm.com/developerworks/library/ba-direct-marketing-spss/.

\footnotetext{
*Corresponding author.

E-mail address: nilesh_k_patankar@yahoo.com
} 